\title{
Zero Discharge of wastewater Treatment Technology of Wet Desulfurization in Coal-fired Power Plants
}

\author{
YunYang Wang \\ North China Electric Power University, Baoding ,China
}

1716970850@qq.com

\begin{abstract}
Keywords: Wastewater of desulfurization, evaporation, wastewater treatment, zero liquid discharge
\end{abstract}

\begin{abstract}
Limestone Wet flue gas desulfurization (WFGD) technology with high efficiency is being applied most widely for control technology of SO2 all over the word. It is widely used in coal-fired power plants, which will produce wastewater containing high salt and heavy metals. Currently, the desulfurization wastewater mainly adopts chemical precipitation process to dispose. but this process has many disadvantages. And the water after chemical precipitation treatment is high salinity, and easily lead to secondary pollution if discharged directly. Therefore, the zero-emission of desulphurization wastewater treatment caused more and more attention. In this paper, the advantages and disadvantages of existing treatment processes are systematically analyzed. And mainly introduced the classification, principle research status and application status of zero discharge of desulfurization wastewater treatment technology based on a comprehensive analysis and summary of the existing literature and reports. Finally,we forecast the research and development direction of the zero-emission desulfurization wastewater treatment technologies.
\end{abstract}

\section{Introduction}

The vast majority of power plants in our country use limestone wet desulphurization technology to remove the SO2 in flue gas. Because of the desulfurization wastewater's complicated composition , many kinds of pollutants, it has been one of the most difficult wastewater to handle. At present, our country mainly adopts chemical precipitation method (commonly known as the triple sedimentation tank)to handle the desulfurization wastewater. The treated effluent is high salt content, likely to cause secondary pollution if directly discharged. Since the amount of the desulfurization wastewater is small, the salt content is high, many scholars at home and abroad began to study the zero discharge of wastewater treatment technology in recent years. This article describes the current desulfurization wastewater treatment technique's advantages and disadvantages, and analyzed the desulfurization wastewater zero discharge treatment technology's research and application status.

\section{Situation of desulfurization wastewater treatment}

More than 90\% from coal-fired power plants in China adopt the limestone - gypsum wet flue gas desulfurization technology at present. In order to maintain the stability of the system and ensure the quality of gypsum products in the wet flue gas desulfurization process, it needs to control the concentration of Cl- to be not too high, so it needs to discharge part of the liquid, resulting in desulfurization wastewater. Most of the power plants deal with the desulphurization wastewater by chemical precipitation method at present, mainly through oxidation, neutralization, precipitation, flocculation process to remove heavy metals and suspended solids from desulfurization wastewater . Chemical precipitation process is shown in Figure 1[1]. 


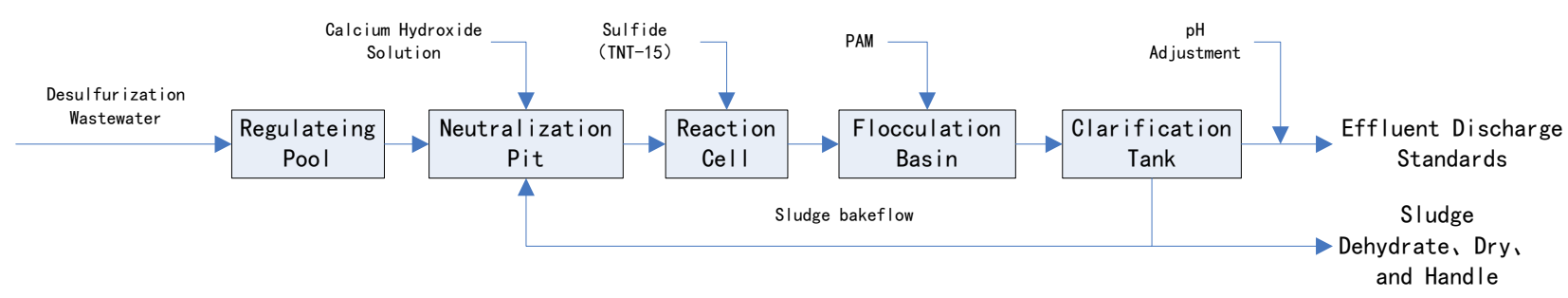

Figure 1 Typical chemical precipitation process of desulfurization wastewater treatment

Chemical precipitation method possesses the advantages of simple operation and low operation cost[2]. But it needs high construction investment and has more equipment[3]. And there are many problems in actual operation, the suspended solids(SS) and the chemical oxygen demand(COD) of the effluent can't often reach the discharge standards stably. In addition, there is a high failure rate of the frame filter press, difficulties of operation and maintenance and other issues through the sludge dewatering process.

\section{Zero discharge of wastewater treatment technology}

The so-called zero-emission is an ideal closed water system. Water in the system cycle continuously or reuse after processing and does not drain out. The zero discharge of wastewater is not discharged to the outside of the system any form to save water resources and protect the environment. The desulfurization wastewater at home and abroad is mainly treated by chemical precipitation, but the wastewater still contains high concentrations of dissolved solids, including chloride, etc,after a chemical precipitation treatment standard. So it's difficult to reuse,generally adopts the method of direct emissions to dispose. However, directly discharging the treated wastewater is not only a waste of water resources, at the same time it will cause changes in physical and chemical properties of soil and water, causing secondary pollution due to the high salt content water. This method will be limited in the future wastewater treatment with the advancement of pollutant emission standards and increasing water pollution control technology. In order to achieve wastewater discharge standard and reuse the water, zero desulfurization wastewater discharge treatment get more and more attention. The core of the desulfurization wastewater zero emissions is the development of desalination technology. It's difficult to achieve good results because of the inhibiting or toxic effects to the microorganism of the high concentrations of salt. So it can only use the appropriate physico-chemical treatment methods. , It mainly includs the following two types of routing in the zero-emission desulfurization wastewater treatment.

\section{Evaporation method}

Evaporation method is one of the commonly used method of zero discharge of wastewater treatment, the method can also be applied to the desulfurization wastewater treatment. The basic principle of evaporation law is that the waste water entering the evaporator heated by steam or electric heating to boiling, and the moisture in the wastewater gradually evaporate into steam. After cooling the water vapor condenses into water again and reused. The dissolved solids in wastewater are trapped in the distilled raffinate and finally precipitated in crystalline form with the increase of concentration. Evaporation method has been widely used in the chemical industry, it may be used alone or in combination with other processes. With the recent advances in water treatment technology, the multi-effect evaporation method of evaporation has been rapidly developed. Because of its high heat transfer coefficient, operating flexibility, simple water pretreatment and relatively low energy consumption, the evaporation method is widely used in chemical, pharmaceutical, desalination and wastewater treatment and so on. 


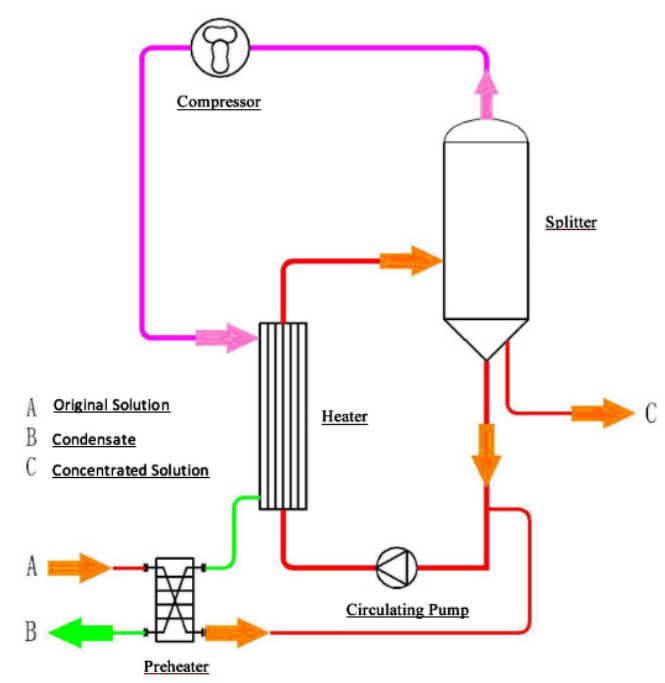

Figure 2 Basic schematic of evaporation method

There is the problem of high energy consumption, easy to scale and large equipment investment, this is also an important factor of limiting their applications. Therefore, you need the following two aspects of wastewater pretreatment to reduce processing costs of zero emissions and ensure the normal operation, namely the reduction of wastewater and anti-fouling treatment. On the one hand, by the reduction treatment method for wastewater pretreatment can reduce evaporation crystallizer handle negative, which can reduce the processing load on the evaporator crystallizer and reduce processing costs effectively. On the other hand, By softening to pretreat wastewater to prevent fouling of the evaporator. In the desulfurization wastewater treatment, commonly used methods include lime softening, soda softening and resin softening, etc, as well as the combination of the method described above.

\section{Flue gas treatment method}

Flue treatment method is a method of spray evaporation process in the flue of waste water[4]. Spray evaporation method is widely used in the food, chemical and other fields, but is seldom used in wastewater treatment. When using flue gas evaporation method to deal desulphurization wastewater, Firstly, the desulfurization wastewater will be atomized and injected to the flue gas before the electrostatic precipitator by a cretain way. Waste water evaporates and gasifies quickly when heated by the high temperature flue in the form of small droplets.And some of the suspended solids and soluble solids form fine solid particles. And then enter the electrostatic precipitator at entrainment gas stream and be removed by the electrode.And ultimately near-zero emissions desulfurization wastewater treatment.

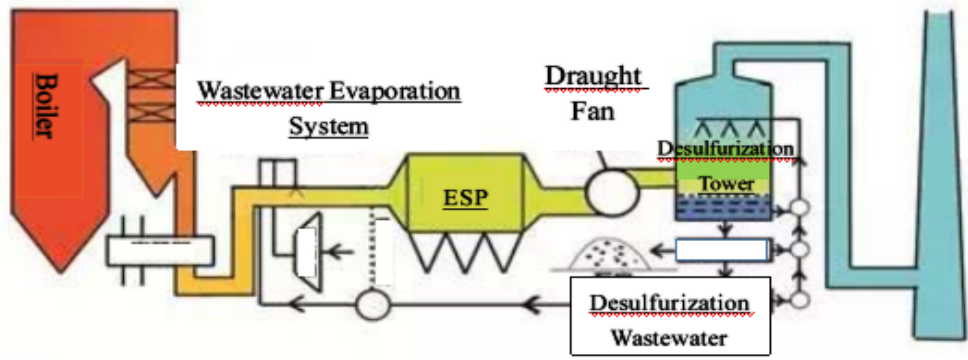

Figure 3 Spray Evaporation Method

Compared with the existing desulfurization wastewater treatment technology, evaporation method has many advantages,such as simple equipments, without adding chemicals, and can effectively overcome the existing wastewater treatment system's more equipment, large investment, high operating costs and equipments maintenance workload and so on. And it's operation is simple, and the pollutants in wastewater discharged in the form of ash, and no sludge disposal problem. Since the introduction of waste water into the flue, it can be an appropriate increase in the flue gas humidity, thereby reducing the flue gas dust particles resistivity. 
In practice, the use of flue gas desulfurization wastewater treatment reported rarely, and only the United States Bailly power plant uses the technology. The main reason is there are many potential problems remain unresolved, such as the impact on the composition of wastewater and other characteristics of the flue gas composition changes, wastewater quality ingredients possible effects on subsequent processing of flue gas produced, and because the inner walls of pollutants in the flue adsorption flue may cause corrosion problems.

\section{Conclusion and Outlook}

In summary, in order to avoid high salinity wastewater pollution of the environment and recycle water, zero discharge of wastewater desulfurization process has accept more and more attention. It mainly includes two methods:

First one is the evaporation crystallization method, which can recycle water and crystallize salt.The high energy consumption is the main reason to limit large-scale applications. Moreover, to ensure the normal operation of the evaporator and crystallizer crystalline salt quality assurance,it needs strict desulfurization wastewater pretreatment methods.

And the second is the flue evaporation method. this process is simple, low operating costs. But it can not recycle water, and there are a lot of potential impact can not be determined, including the impact on subsequent processes, such as dust, and may cause flue corrosion problems. Thus, in the flue gas desulfurization wastewater evaporation processing. Thus, the processing in flue gas desulfurization wastewater evaporation, research should focus on the impact of waste water of flue gas emissions and flue gas treatment system into the flue. Flue gas treatment method to be widely used, but also for a large number of long-term and comprehensive economic and technical research and evaluation.

\section{References}

[1] Liu H Y,Xia H X,Jiang C Y,et al. Research Advances in Wet Flue Gas Desulfurization Wastewater Treatment Technology in Coal-fired Power Plant. Water Pollution Control. 2016,31-35.

[2] He Z Q,Qi L M. Coal-fired Power Plant Flue Gas Desulfurization Wastewater Treatment Process[J].Technology of Water Treatment.2010,36(3):133-135.

[3] He S D,Li R,Zhang Z M,et al. Summarization of Non-discharge for Water-saving and Waste Water in the Power Plant[J]. Environmental Science and Management.2008,33(9):23-25.

[4] Ma S C,Chai F,Wu W L,Hua J Z,et al.Numerical Simulation of Flue Gas Desulfurization Wastewater Spray Evaporation.Computers and Applied Chemistry.2016,47-53. 